\title{
ERRATA
}

\section{Kinetics of Nitrate and Ammonium Uptake by the Natural Populations of Marine Phytoplankton in the Surface Water of the Oyashio Region during Spring and Summer}

\author{
Akihiro Shiomoto, Katsuyuki Sasaki, Toru Shimoda and Satsuki Matsumura
}

Journal of Oceanography, Vol. 50, pp. 515-529

Figure Legends

Figures 1, 2 and 3 should be read as follows;

Fig. 1. Location of sampling stations in the Oyashio region. Spring stations are denoted as Stas. 1,2,3 and 4, while those of the summer as Stas. 5, 6 and 7.

Fig. 2. Vertical profiles of $\sigma_{t}(\Theta)$ and concentrations of nitrate $(O)$ and ammonium $(\Delta)$ shallower than 100 $\mathrm{m}$. Arrows indicate the depth of the euphotic zone (the $1 \%$ light level).

Fig. 3. Uptake rates as functions of nitrate and ammonium concentrations in the spring (a) and summer (b). Arrows indicate the ambient nutrient level before tracers were added. 